\title{
En torno al mundo \\ islámico de Melilla
}

JUAN ZOZAYA

DEFINICION DEL TEMA. SIGNIFICACION DE "ENTORNO ISLAMICO".

LA LSCASEZ DE FULNTLS ARABES RHFERIDAS A MELILLA

No es en absoluto fácil definir algo que por definición es indefinido. En "torno a" es una locución que se usa como elemento que significa "alrededor de...", porque no hay un centro, un objetivo claramente definido, y por lo tanto hay que realizar giros en torno a él. Está otro aspecto: el meramente topográfico. No tenemos definido el territorio. No sabemos muy bien definir en dónde ocurren los hechos; pero sabemos que hay un lugar "en torno al cual" pueden situarse unos hechos, que no sabemos muy bien si ocurren o no. Tenemos que aceptar que el lugar definido puede compartir, o no, hechos con los lugares de su entorno, pero desde luego es dable aceptar que los problemas de un mismo ámbito interactúan en mayor o menor grado.

Es difícil pensar que las relaciones de la España medieval cristiana con el mundo musulmán no tiene relación con la costa septentrional del Africa Menor, de éso que los geógrafos musulmanes describieron como al-Magrib al-Aqsa. De hecho la justificación histórica de los contactos más o menos violentos de la Europa sud-occidental con la zona de la costa norafricana 
se basa en la necesidad de mantener los contactos económicos entre los dos continentes, muchas veces por motivos que van más allá de lo inmediato.

Ello es lo que permite definir que la ausencia de fuentes respecto a Melilla puede traspolarse a la zona inmediata formada por varios elementos geográficos y que son, sucintamente: primero el eje Tlemcen-Nakur-Melilla-Ceuta como dominante del área del Mar de Alborán y por otra parte el acceso del hinterland por el Uad al-Muluya hacia Taza y el valle de Fez, núcleo comercial de primer orden y que está en contacto total con el área de comercio con las caravanas que cruzaban el Sudan Occidental y que procedentes del mismo traían oro, plata y marfil, objetos raros en Europa y cuyo monopolio podría dar un papel importante a quien lo detentara, a jugar en la economía europea desde el final del Alto Medievo hasta el comienzo de la modernidad, papel cambiado radicalmente por el descubrimiento de América. Por ello se hace necesario comenzar por la descripción de la zona en cuestión.

MELILLA Y SL WNTORNO GEOGRAFICO. LAS CONDICIONANTES GEOGRAFICAS

EN LA ECONOMIA DE MELILLA EN ÉPOCA ISLAMICA

Melilla se encuentra en una península y cabo en la costa norte de Africa, denominada de las Tres Forcas, en el Africa Menor, en la zona mediterránea magribí, surgiendo como remate en el Mediterráneo del espinazo del Atlas Medio, el Atlas teliano, arranque del espinazo discontinuo del Rif. En torno a ello, y en la zona costera se desarrolla una economía de huertas, pesca rica entre el Cabo Bon y Gibraltar y comunicaciones con el vecino europeo del norte.

El relieve de toda esta banda es elevado, agreste, torturado y rocoso, con raras llanuras. El régimen de lluvias depende del relieve, y los ríos de la fachada mediterránea suelen secarse en verano. De caudal constante, y entre los ríos más importantes de la zona son el Meyerda, el Chelif y el Muluya, siendo éste muy próximo a la ciudad objeto de nuestro interés, que queda entre éste y el Uad Kert. Melilla propiamente dicha tiene conti- 
guo el lecho estacionalmente seco de Río de Oro, referencia posible a los detritus que trae desde la zona geológicamente rica de los cerros del Rif.

Se sitúa, como se ha dicho, al lado $\mathrm{S}$ del cabo de las Tres Forcas (Ras Werk, antiguo Ras Hurk de los geógrafos clásicos árabes), en el istmo rocoso de Gel iyya que une al cabo citado con el continente, que le permite una zona guarnecida de los aires de poniente, buena defensa y dominio de una amplia zona sobre el lado de levante de la costa. Tiene pequeña zona de huertas, pero su economía fue, aparte del comercio, la de la producción de sal, el hierro de las vecinas minas y las perlas de la zona.

Este pequeño cabo / península tiene un papel modesto pero continuo a lo largo de la historia, y no va ser menor el que tiene a lo largo del dominio islámico del norte de Africa y durante el período que estuvo sometido a ese régimen legal.

Las corrientes marinas que le afectan del lado de poniente son las procedentes de Gibraltar, las que siguen las sardinas, los atumes y los delfines para entrar en el Mediterráneo desde el Atlántico hacia sus desoves en las costas de Turquía. Estas mismas corrientes son las que facilitan la navegación de entrada al Mediterráneo, mientras que las de salida han de hacerse por la costa mediterránea de la Península ibérica. Estas corrientes son las responsables de diversos hechos históricos a los cuales aludiré con más detalle pero que se pueden resumir en las navegaciones normandas hacia Bizancio.

SIGNHFICACION DF MEIIIIA. SI PAPEI. EN REIAACION CON LA LIEGADA DIE

I.OS IDRISIES. WAIIIA Y VALILA: ZUN PROBIAVA DL GRAFIA ARABE?

El topónimo de Melilla tiene diversas atribuciones, siendo la más común la de referir a Melilla como lugar de Miel, la melosa, etc. pero la raíz $\mathrm{M}-\mathrm{I}-\mathrm{I}$ no parece concretarse en tal significado. Teóricamente hubo una población ibera que le dio el nombre de Mlila, hecho dudoso, pues está aún por demostrar la presencia ibera en esa zona. El término actual se refiere a Mlilya. Algunos arabistas derivan el nombre del beréber Tamlilt "la blanca". Entre los geógrafos árabes clásicos fue conocida como Malila. 
Curiosamente, y como se podrá apreciar posteriormente, en las cercanías, y en momentos de la llegada de los Idrisíes al Magrib existió una capital denominada Walila, en las cercanías geográficas de la actual ciudad, que desaparece coincidiendo con la caída de los idrisíes. Cabe pensar que hubo un cambio intencionado de grafía, una "confusión" de escribano, respecto a Walila-Malila, pues el "Waw" permite ese error gráfico. No deja de ser notable la desaparición del tema de Walila y la consecuente aparición de Malila. Es una secuencia en el tiempo curiosa mientras que no desaparece Nakur hasta tiempos más tardíos.

¿Cuáles son los elementos conocidos de historia de Melilla y su "hinterland" a partir del comienzo de la islamización del Magrib? No hay noticias concretas entre los siglos VIII y el IX. Se sabe que a mediados del siglo VIII un árabe del Yemen se traslada al valle de Alhucemas a una ciudad recién fundada que se denominará Nakur y en donde se establecerá el reino independiente de los Banu Salih. Nakur tendrá una importancia notable en el proceso de islamización de la zona rifeña, extendiéndose hasta Badis (Vélez de la Gomera) y por el E hasta el río Muluya.

Muhammad b. 'Abd al-Allah b. Hasan b. al-Hasan b. 'Ali b. Abi Tālib se levanta contra el Emir Abu Yaufar al-Mansūr al-Abbasi en el Hiyaz en el 752. Emigra a Sudan, derrotado, rebelándose en Mekka. Tiene seis hermanos y envía a cuatro a propagar sus ideas y la obediencia del pueblo a él. Uno de esos hermanos, 'Isa, va a Ifriqiya. Cuando muere su hermano, Muhammad se subleva y es derrotado en la batalla de Fajj (786). Uno de sus hermanos, Idris, huye a Egipto, y tras muchas aventuras él y su liberto llegan a Qayrawan y de allí al Magrib vía Tlemcen, siendo su destino en el Occidente Tanger. De allí por el río Muluya baja al Sus. De Tanger retrocede a una ciudad denominada Walili, anteriormente citada. Era una ciudad "rica en aguas, plantíos y olivares, que tenía un muro muy grande de fábrica antigua". Esta ciudad de Walili aún permanece inidentificada hoy en día, citándose como topónimo mas similar una tal 'Ain Walili cercana a Mulay Idris.

Idris se levanta en Walila en 789 y es proclamado por las kabilas de Awraba, después por los Zanata, Zuagas, Zuawa, Lmaya, Luata, Sadrata, 
Agyata, Nafza, Miknasa y Gomara. En el 789 amplía su radio de acción y muchos cristianos y judíos se islamizan. Toma Tlemcen, en donde edifica una mezquita. A partir de aquí tenemos pocos datos.

I.AS NAVEGAGIONES NORMANDAS AI. ENTORNO DE MEIIII.A. SIGURD JOSAL. FAR Y SL EXPEDICION A BIZANCIO

789 Ciomo muy bien dice (Mir (1965) "de esta época tenemos pocos datos fidedignos del desarrollo de la antigua Melilla... debió alcanzar un floreciente comercio pero sufrió serio quebranto el año 859 en que entraron los vikingos en el Mediterráneo, saqueando numerosas poblaciones del Norte de Africa, y entre ellas Melilla, que fue incendiada".

El 866 se repite un ataque sobre Nakur, que posiblemente debió afectar a Melilla, por su proximidad y por el comercio anteriormente citado de perlas. El texto es claro: "Iterum nordomani piratidae per haec tempora ad nostris litoribus pervenerunt; deinde in Spaniam perrexerunt, onmenenque eius maritimam gladio iqueque paraedando dissipaverunt; exinde mare transiecto Nachor civitatem Mauritaniae invaserunt, ibique, multitudinem Caldeorum gladio interfecerunt. Denique Maioricam, Fermentellam et Vinoricam insulas adgressi, gladio eas depopulaverunt. Posteam Greciam admeti, post trienium in patria sua sunt reversi" (Cron. Alf. III, $\mathbf{n}^{\mathbf{0}} 26$ ).

Otra expedición normanda vuelve a tocar la misma zona, siempre como consecuencia de su entrada en el Mediterráneo camino de Bizancio, en torno al 910, aunque aparentemente a partir de esta fecha, y hasta la mas tardía del héroe noruego Sigurd Josalfar en 1107 no hay más ataques de este tipo. Este personaje atacará Nakur también, y de allí atacará Ibiza y Formentera, en donde deja la memoria de la Cova del Fum, pues parte de la población musulmana se refugia en una cueva y los ahuma para expulsarlos de ahí, por lo cual queda el nombre. 
Las luchas contra los idrisíes en torno al 950 nos traen a colación a Melilla. 'Abd al-Rahman III tuvo marcado interés por el control del Magrib, especialmente con dos ideas fundamentales: el control occidental de los accesos al oro de Sudan y al marfil africano, así como la contención de los fatimíes en Occidente, acompañada de los influjos ideológicos del ši ismo. Según las fuentes las ideas de 'Abd al-Rahman III van orientadas hacia Africa y vienen desde el 912. como dirá el Muqtabas VII. El 917 es efímeramente ocupada por los fatimíes. Sin embargo no son claras para momento tan temprano, pero desde el 928 los aspectos son evidentes. Veamos algunos rasgos.

En efecto: Muṣa b. Abi-l-'Afiya al-Miknasi, en el 925 se apoderó de Fez. Tanger y Basra, dominando todo el Magrib, reinando en Taza, Tsul, Lukay, Tanger y Basra, extendiendo su poder por todo el Magrib, desterrando a todos los idrisíes de sus tierras, tomando Arcila y Challa, refugiándose todos los si iesen al-Hayyar al-Nașr (La peña del Aguila) en donde son sitiados. Eventualmente va a Fez y a Tlemcen, que somete. Su gobernante, al-Hasan b. Abi-l-Aiŷ b. Idris al-Hasani se refugia en Melilla (931). Ibn al-Afiya, tras apoderarse de Tlemcen se dirige a Vakur y sus dependencias en 952. Una vez tomadas Tlemcen, Nakur y Fez proclamó al rey de al-Andalus al-Nasir li-Din Allah. Ello provoca el ataque de Ubayd Allah al-Ši ${ }^{i} i$ desde al-Mahdiya.

El año 929 marca la proclamación de Abd al-Rahman al Califato de Occidente. Sunní, mira hacia el norte de Africa, lugar de procedencia del oro y el marfil, fundamentales para el comercio y el sostén del gobierno, un año después de haber comenzado a acuñar plata y oro después de mucho tiempo, según reza el Muqtabas V. Para ello se basa en lo problemas religiosos, con lo cual justifica el control del estrecho con Ceuta. Para ello ataca a 'Lbaydalla, rebelde en el norte de Africa, cosa que hace en el propio año 929. para lo cual entra en contacto con el emir de los zenetes, Muhammad b. Jazar. De esta manera empieza a articular su lucha contra la S'ia.

Los ataques se realizan en torno a la zona costera desde Oran hasta Ceuta. Paulatinamente se van avanzando hasta el Este, tomando plazas 
como Tenes o Chelif. Un tal Mansur b. Sinan ese año remite regalos a 'Abd al-Rahman III de caballos, camellos, gacelas y ganado. Un personaje de un linaje que se mencionará posteriormente con continuidad es Musa b. Abi l-'Afiya, que en el 930 hace llegar a $\mathrm{Abd}$ al-Rahman las cartas de lealtad.

Entre los jerifes alauies auténticos el Muqtabas V cita a Idris B. 'Abd Allah b. Hasan b. al-Husayn b. 'Ali b. Abi Talib, Idrís, cuya historia, breve, cita. Menciona los problemas dinásticos y el Señor de Rasgun, Idris b. Ibrahim al-Sulayman al-Hasani, que se pasa también al partido de 'Abd al-Rahman. Igualmente parecen pasarse al bando omeya personajes que no habían aceptado el si'ismo, entre los cuales estaba también al-Qasim b. Ibrahim al-Hasani. Otro de los añadidos fue al-Hasan b. 'Isa al-Husayni que pidió ayuda y reconoció afecto al año siguiente (931). Los regalos que al-Husayni remite son espléndidos y mencionados en el $\mathrm{M}$. $\mathrm{V}$ por su lujo: “... 25 corceles norteafricanos, de ellos dos purasangres excelentes para su uso con aparejo pesado, 23 camellos de raza, entre ellos uno de gran talla. con perfecto físico y jaez, propio de reyes, con palanquín baldaquinado en cenefa de plata y tela de brocado tustari forrado, un cinturón adorando en plata, diez carneros damaíes de los mejores de su especie en Sudán, dos hermosas gacelas y ocho avestruces, regalo como nunca hicieran los reyes de al-Magrib y al que al-Nasir correspondió largamente" (MV 176).

El 930 Muhammad b. Jazar; príncipe de los cenetes jura fidelidad a :Abd al-Rahman. Se considera perseguido, habiendo tenido que disimular sus sentimientos, pero en ese momento se siente capacitado para obedecer al califa "Dejé, pues, la indulgencia y preferí la verdad, refugiándome con intención sincera y visión penetrante en el príncipe de los creyentes, pues de todos me desentendí salvo de él y negué todo otro imán, esperando que Dios me ayude por su causa..." y después "... pues tu, oh califa, eres señor de todo beréber en la tierra, puesto que fueron los omeyas quienes los condujeron al islam, y sus ejércitos los que en él les metieron, sacándolos de la idolatría, por permisión divina" (MV 177).

Para ello acompaña la carta de una adecuado obsequio: diez dromedarios capones de sorprendente complexión de clase selecta, con sillas, ronzales, riendas, gualdrapas, púrpuras y arzones, que levaban colgadas diez 
preciosas adargas de ante, veinte camellas preñadas, algunas de diez meses, con su excelente semental de alta complexión y su pastor, un esclavo negro experto en el cuidado de los camellos y sus aparejos, dieciocho corceles marroquíes, uno leonado con crin negra, otro alazán, de cinco palmos, con lucero y calzado, y otro ceniciento, de cinco palmos con rosetas en las orejas y extremos de la cola, cuatro purasangres a los que no se les podía quitar ojo, superiores a todas las monturas de an-Nasir... dos fieros leones con su leonero y cuatro avestruces" (MV 178).

Corresponde "Abd al-Rahman III con vestidos de su tiraz, bordándole en ellos "Muhammad b. Jazar", cosa no hecha antes con nadie. "Diez piezas "ubaydies... tal cual nunca se hicieran en las manufacturas abbasíes ni otras... además de 50 superiores, junto a una cortante espada de modelo franco, adornada en plata, dorada y con relieves, en una vaina de lija, con contera y funda de plata pura trabajadas, con grandes cordones al estilo franco adornados con oro y pedrería de la misma hechura, en número de 24 gemas, con correa recubierta de brocado tustari verde y espuela de oro con espigas granuladas y adornadas las puntas con grandes perlas, un ceñidor de oro en forma de cinto de correa sino-iraquí, adornado con grandes perlas junta a las gemas y en la punta, con veinticuatro gemas de punta adornada y una hebilla con ocho gemas unidas por encima en el extremo libre, con grandes perlas en el extremo, decorada con valiosos jacintos" (MV 178-179).

Las dudas de 'Abd al-Rahman III se incrementan respecto a las capacidades de actuación autónoma de los régulos beréberes en el Magrib, y opta por el establecimiento de una especie de Protectorado, para lo cual decide controlar el Estrecho, tomando Ceuta, evidentemente, como se diría acudirá (y así lo dice el Muqtabas V) por petición de la población local, pasando al gobierno del gobernador de Algeciras, el general Umaya b. Ishaq, que se hace con el gobierno ceutí en marzo del 931, invitando a los régulos vecinos a él a unirse, haciéndolo Muhammad Abi-l-'Afiya, de los cenetes, Mansur b. Sinan. Zakila b. Sisay (Tánger), al-Mu'ayyad b. 'Abd al-Sami', por Nakur y Nafza, en fin las kabilas de los Lamsa, Anyara, Masmuda y Mayhasa, toda la zona de la costa, dentro de la cual hay que presumir se incluye a Melilla, manteniéndose en contra, en rebelión, los hasaníes. Sin 
embargo, de manera relativamente pronta 'Abd al-Rahman III recibe carta de los Idrisíes afectando lealtad.

El Califa escribe a los príncipes del N. de Africa la necesidad de aliarse y para intentar recuperar el trono de Oriente. Para ello apresta una flota que navegue a Ceuta y otra a Orán. Los arreglos políticos sufren problemas de celos internos, disputas territoriales, etc. que son arreglados mediante diplomacia en principio, siempre con el añadido de regalos, generalmente caballos con sus arreos, ropa y tejidos y armas, especialmente espadas y ocasionalmente sillas con pedrería. De hecho, y este es un dato interesante, la zona bajo la demarcación de Ibn 'Afiya suspende la circulación de moneda fatimí, admitiendo sólo la del Califato, del cual Ibn 'Afiya sería un ejemplar aliado.

Ese año al-Hasan b. Abi-l-'Aiy b. Idris al-Hasani huye de Ibn Abi-l-'Afiya a la ciudad de Melilla, en donde se fortifica. Aparentemente Abi-l-'Afiya toma toda la zona como parte de su ayuda (mutua) a "Abd al-Raḥmān III, a quien proclama. La prédica de su nombre llegó a hacerse en Fez, Tlemcen y Nakur.

La flota se organizó desde Pechina y Almería, con 120 unidades y más de 6.000 efectivos, y en ella va a participar un personaje que tendrá un papel preponderante en el Norte de Africa: el almirante Muhammad b. Rumahis. La expansión califal, por otra parte, tuvo su ampliación hacia Arcila el año 933. Los modos militares de actuación hacen que los si'ies sean rechazados hacia Tahart.

Fez seguía en la lealtad a 'Abd al-Rahman III, especialmente por las acciones de Ibn 'Afiya que recibe una serie de regalos y cuya enumeración merece la pena seguir. Es excepcional, pero no por ello deja de ser interesante: 25 piezas tirazi, de las que 5 eran 'ubaydi iraquí, 10 tirazi, 3 de lana marina, 2 zaragozanas y 5 turbanes, 1 gran escriño califal de plata, con planchas en relieve dorado, fondo blanco e interior revestido de púrpura. Nueve botes y cajas llenos de diversos perfumes, entre ellos un bote de plata, lleno de sándalo mezclado con ámbar, un bote de marfil blanco con incienso aderezado con ámbar, otro bote de marfil también con bisagras de plata que contenía una vasija iraquí llena de excelente algabia, una tercera 
caja de marfil con bisagras y techo plano con perfumes reales, una caja de vidrio con tapa y cadena de plata, con el polvo que los reyes utilizan para el sudor en verano, una botella iraquí dorada con agua de rosas iraquí califal, una funda de raso con un gran peine de sultán para peinar la barba, un pincel de oro para colirio envuelto en su paño ajedrezado, forrado en raso y recubierto de cuero de $\mathrm{Fez}$ de excelente labor, con cuatro compartimientos, en cada uno de los cuales había una caja de plata de hechura franca, una encerada y con cuello ajedrezado con tapa y cadena de plata, una tercera similar y una cuarta del mismo trabajo que la primera, con los cuatro excelentes purgativos califales, carquecia, hierba amarilla, hierba blanca y sudorífero, y que en la cavidad de estas cajas había también una botella iraquí con ungüento califal, y un pequeño escriño de plata con mondadientes y los aparejos que usan los reyes para después de comer".

A ello se añadían armas peregrinas, entre los cuales cuatro estandartes, seis atabales dorados con todos sus accesorios y soportes, en funda de cuero rojo, forradas en lana y 20.000 dardos cristianos (MV 238-239).

El 936 sigue la situación, con Tanger en la desobediencia, Tahart se rebela a favor de 'Abd al-Rahman III, los abbasíes derrotan a Musa b. 'Afiya y 'Abd al-Rahman III manda la flota para apoyarle, y de Ceuta va a Melilla y Nakur, conquistándolas, para de allí ir a Yarawa, que también toma. El 937 Musa explica todo por carta al califa y le pide ayuda para hacer una fortaleza en Yara. 'Abd al-Rahman manda a su proto-arquitecto Muhammad b. Walid b. Fustayq, con 30 albañiles, 10 carpinteros, 15 cavadores, seis hábiles caleros y dos esteros, acompañados de cierto número de herramientas. A ello añade elementos clave para sobrevivir (pues b. 'Afiya debió quedar mal y sin recursos) trigo, cebada, habas, garbanzos, higos, miel, manteca, aceite y añade ropas de lujo, tapices, cojines, un pabellón de cuero de 30 albanegas con tienda de retrete, un lecho de raso, almohadas 2 tiendas. b. 'Afiya va avanzando, matando a los infieles pero respetando a "súbditos y personas inocentes, como comerciantes y otros". La crisis vendrá con la muerte de b. 'Afiya en el año 938, haciéndose cargo de su papel su hijo Madyan, que ve renovada su autoridad sobre, entre otros distritos, los de Melilla, que le habían sido reconocidos a su padre. 
El 940 'Ali b. Hamid al-Miknasi, caid del Señor si'i de Ifriqiya solicita obediencia a 'Abd al-Rahman III, que accede, enviándole, como no, un magnífico regalo, y empezamos ahora a ver el desfile de personajes del Magrib por Córdoba, en donde son recibidos. Se producen desavenencias, como la guerra entre al-Miknasi y Muhammad b. Jazar al-Zanati, aplacada por el califa cordobés mediante los ya habituales regalos de autoridad. Incluso llega una delegación de Argel pidiendo la obediencia. Ello hace presuponer que toda la zona de la costa, al menos. desde aquí a Tanger y Arcila está en una obediencia más o menos estable respecto al califato cordobés, y ello incluye, obviamente, a la zona de Nakur y Melilla.

Posiblemente antes del 948 es tomada por los beréberes Banu Urtedi que la dominan, pero no añaden nada en especial. A partir de allí parece haber un vacío en las fuentes hasta la década de los setenta. El Muqtabas VII no da noticias hasta el año 971, en que veremos cómo esta banda costera del Magrib da problemas, que el nuevo califa, Al-Hakam II, resolverá más por la guerra que por la diplomacia, lo cual dará importantes datos sobre la situación en esta zona:

a) las lealtades diplomáticas no pueden mantenerse exclusivamente con regalos y se procede a una sistemática guerra de ocupación

b) aparecen con relevancia dos personajes importantes en la historia del califato: uno es un mal militar pero excelente intrigador, un tanto fátuo, lo cual será al final motivo de su pérdida política y vital, que es Galib y el otro más taimado y callado, gran administrador, capaz de urdir la trama del poder, que es Muhammad Ibn Abi 'Amir. fundador de la dinastía 'Amirí, que será más conocido como Almanzor

c) el paso a prácticamente obtener rehenes como sistema de mantener lealtades

d) la berberización inicial del califato que tanto contará a la hora de la fitna cordobesa.

e) un gasto enorme de dinero en la guerra, ya incidente a partir del año 957, y que produce una falta enorme de conocimientos hasta que comienza este dispendio, y que producirá una inflación en Al-Andalus. 
El 971 el gobernador de Masila (actual Muhammadiya) se aproxima al trono cordobés. Mucha gente viene a Córdoba, y se organiza un gran alboroz militar para recibirlos, dando la impresión de tratarse de un momento en que hay que "hacerse perdonar" muchos pecados mientras que el califato da, quizás, su primera impresión de incapacidad de control de la zona.

Por lo pronto el 972 Rumahis ha de ir con la flota y conquistar Tanger, que obviamente para entonces ha dejado su obediencia a Córdoba, y de allí se ataca Arcila, que también será tomada. al-Hakam II envía a Berbería dos alamines con la única misión de acordar a las diferentes tribus. Ello no implica que no haya problemas. Ese mismo año Ibn Tumlus, leal a Córdoba es muerto a manos de lbn Guennun. El 97370 jefes van a Córdoba a presentar su obediencia a al-Hakam II, Ibn Guennun habla de hacer la paz, pero el califa desconfía y declara la guerra como solución, estableciendo una política de atacar a la persona pero no al pueblo, individualizando así el castigo por herejía, para lo cual consigue montar toda una compleja red de información.

El califa hace que Galib ibn 'Abd al-Rahman se encargue de la guerra en Berbería dado el poder que va adquiriendo B. Guennun. Los caídes de Marruecos reciben orden de suspender sus actividades y dejar la iniciativa a Gālib. Simultáneamente se recibe un parte de victoria de los caides con la toma de Arcila. Al-Aqlam y al-Qarawiyin piden entrar en obediencia y el propio mes de abril, en el cual se han producido estos acontecimientos se manda dinero para pagar a las tropas del Magrib y 10.000 dinares destinados a regalos a los notables y jefes de kabilas que dejen la obediencia a Ben Guennun, así como regalos diversos de ropas y armas.

Ello provoca que se pase la familia de Ben Guennun, que va a Córdoba con su familia, celebran circuncisiones de familiares suyos apadrinadas por el califa y se consigue que grandes conjuntos de militares se pasen al califato. Asi, por ejemplo Ibn Bilal, jefe de Kutama, zona vecina a Melilla, comandaba 3500 jinetes y 6400 infantes, lo cual consitutye un más que notable ejército para la época. Se producen medidas económicas como suprimir impuestos, no hay azaques sobre dimmiíes, sólo se paga el impuesto de capitación y en el de comercio de un país con otro, pero sin cobrarse peaje a viajeros ni pasajeros. 
En mayo se regaña a los caídes y a Ibn Rumahis por retrasarse en la fortificación de Tanger, y se remiten 80.000 dinares para pagar a los cuerpos de dicha ciudad. En Julio (apréciese cómo de deprisa discurren los hechos) Galib ataca a los Yuwara, y huye b. Guennun y se incorporan 1.700 tropas toledanas, equipadas con espadas cristianas. En julio regresan los alamines de Berbería, pero uno, Muhammad Ibn Amir recibe la orden de regresar a esta parte del país, de donde es designado Jefe Supremo, manteniendo su puesto de Cadi de la Cora de Sevilla. Hábilmente incorpora a los Banu Jazar que estaban residentes en Córdoba (¿por desconfianza o por pérdida de sus territorios?) a la lucha en Berbería de manera que ayuden a sus contríbulos a pasarse a la obediencia de al-Hakam II.

Galib empieza a enviar cartas con frecuencia hablando de escaramuzas, de la incorporación en julio a la obediencia de Basra. En agosto se envía a Muhammad b. Hasim al-Tuyibi, castigado hasta entonces con residencia forzosa en Córdoba, para ayudar a Galib en el Magrib. La Crónica, para el mes de setiembre, que hasta ahora ha tratado de mala manera a b. Guennun, de repente hace un giro extraño y habla de la incorporación de una tal "Ahmad ibn 'Isa, jeque de los Banu Muhammad, conocido por Guennun" a quien se le dan, entre otras cosas, 7.000 dinares por pasarse, amén de diversos regalos como telas, espada, corcel, \&c. Su hermano Ibrahim recibe también una generosa dote.

A fines de mes Galib comunica la toma de Yabal al-Karam (Hisn al-Karam), una fortificación de b. Guennun, y la huida de éste a la ya citada fortificación de Hisn al-Hayyar. Los costes debieron ser altos, pues Galib recibe desde Córdoba la orden de poner a producir las tierras de sus dominios, pues no se pueden mandar víveres, aunque si dinero. Se le previene que no puede volver hasta que extermine a sus enemigos. Mientras tanto Ibn Abi 'Amir escribe diciendo que el fin del Ramadán ha sido feliz. Galib, a fines de mes, pone sitio a Basra, que cae por rebelión interna de sus habitantes contra el poder. La lectura atenta habla de sucesos acaecidos rápidamente, violentos, poca coordinación entre Galib y Abi 'Amir, y un cierto caos contínuo. 
Para octubre se obtiene la sumisión de los Rahuna y Galib dice que todo el Magrib está sumiso, tomándose también Yabal al'Uyun, al lado del reducto de al-Hayyar. Los jeques de Basra van a Córdoba a rendir pleitesía, y constituyen el principio de toda una serie de embajadas que se producirán hasta el fin de año, en que el hermano de Guennun, 'Isa al-Hasani viene a Córdoba, en donde se recibe también el obsequio de caballos remitidos por el señor de al-Qarawiyīn.

El año intenso se continúa el 974. En enero se recibe carta de Galib, se remiten dineros al Magrib, hay un regalo de camellos de los Banu Jazzar, y se pide dinero para los pobres y menesterosos, lo cual parece indicar, junto con el dato anteriormente recogido de la falta de víveres. una depauperación del territorio por las guerras continuas y la dirección del gasto estatal.

Marzo ve nuevos regalos y más dinero, se autoriza el retorno de los embajadores berberiscos al Magrib. En abril llega a Córdoba Ibn Ya'la, señor de los Banu Ifran y b. Guennun es capturado y remitido a Córdoba, lo cual parece indicar una política de pactos y alianzas que deja aislado a éste, quizás entregado por algún compañero suyo. Abril sigue con remisiones de dinero y Muhammad b. Abi 'Amir es nombrado jefe de la ceca. Mientras Galib obtiene el juramento de fidelidad de los señores de Fez.

La política de rehenes ya es un hecho abierto, y en agosto llegan los de Ibn Yahya de al-Andalusiyin de Fez, los del Emir de Gomara y los rehenes remisos. Galib ordena pasar a al-Andalus a los últimos idrisíes, siendo prácticamente su último acto en el Magrib, pues a final de mes se le ordena que retorne, dejando el mando a Muhammad al-Tuyibi. En ese momento se remite dinero, regresa ibn Suhayd, cajero de viaje, que había tenido ocasión de haber subido al castillo de al-Hayyar "... y había hecho su medición, que trajo, conforme a las ordenes recibidas". Se mandó un cajero pagar a las tropas de Marruecos, cosa que se vuelve a hacer en marzo. Mientras tanto la política parece cambiar. Se carece de más noticias así de detalladas para el resto de los años, parece cobrar más importancia la guerra contra los cristianos del norte, y parece haber una política más suave con los beréberes en al-Andalus. 
Las referencias que hemos visto a la zona, las menciones a Melilla o su entorno inmediato y los resultados de la política califal del $\mathrm{X}$ parecen indicar un dominio de Melilla sobre Nakur, que prácticamente no es mencionada, reino que parece decaer entonces y que es destruido, como ciudad. por los almorávides, dejando de manera lánguida a Melilla.

Entre los personajes que intentan hacerse con el poder en al-Andalus como consecuencia de la fitna se refiere Ibn Hazm, el gran relator del fin del califato, hay varios que adoptaron el título de Mahdi, "Al-Mahdi [da varios en Oriente y cita entre ellos a]: 'Abd al 'Aziz b. Ahmad b. Muhammad b. al-Asbag b. al-Hakam al-Rabadí, en Melilla, del país de Melilla" (Ibn Hazm: Naqt al-Àrus p. 65.).

$Y$ añade:

"Los que se sublevaron en al-Andalus con la aspiración del Califato, a pesar de que otros hermanos suyos, de mayor edad, podían alegar mejor derecho para pretenderlo". Entre los que se sublevaron como Omeyas en al-Andalus cita:

"Abd al-'Aziz b.Ahmad b. Muhammad b. al-Asbag b. al-Hakam al-Rabadi se rebeló en Melilla tomando el título de califa. Fracasada la revuelta, vivió [el resto de sus días] como un hombre vulgar, muriendo dos años después. Sus hermanos 'Abd al-Malik el jurista y Hisam, que le llevaban dos años de edad, [vivían cuando aquél se rebeló y aun] vivieron algún tiempo después de su muerte". Ibn Hazm: Naqt al-Àrus p. 65.

Entre 1067 y 1081 se desintegra el reino de Fez y el de Nakur. Muhammad b. Idris es invitado a ser rey de Melilla, estando en Málaga, y es el pequeño influjo hammudi de Málaga que hay sobre esta zona, pero desaparece con la llegada de los almorávides, que toman Melilla y de manera definitiva destruyen Nakur en 1081. Se carece de noticias para el momento entre 1081 y 1142. 
En 1142 Tasfin tiene un encuentro con los almohades en al-Fallay contra el jefe Yahya Agwal, lo mata, remite su cabeza a Fez. Tasfin va a al-Maqarmada. Al-Baidar y lo suyos, huyendo, van a Gaiyata y después a 'Afra, en donde quedan 50 días con sus noches como consecuencia de una tormenta. Esta destruye la Bab al-Silsila fasi y se corta la península que une a Melilla con el continente. las crecidas de los Wadi Sabu y Wadi Warga se llevan las tiendas de los Lamta. Al-Baidaq narra diversas incidencias y de cómo diversas tribus van paulatinamente dejando la lealtad a los almorávides y se van pasando a los almohades, cómo el Emir de los Creyentes ordenó la partición de los sectores del campo según los estandartes, teniendo cada tribu su estandarte.(Memorias de al-Baidaq).

Sigue "Algún tiempo después Âbd al-Rahman b. Zaggu dejó nuestro campo e hizo camino hacia Melilla con un ejército. Sitió la ciudad y la demolió". Se reúnen las tropas en Hamis Amtalilli y el Califa reparte el botín y en él se hayan cien vírgenes libres de toda violencia. El califa las reparte entre los almohades que se desposaron con ellas, hasta que al final no quedan más que Fatima, hija de Yusuf, el Zanate, y la hija de Maksan b. al-Mu'izz, señor de Malila. "El califa echó a suertes Fatima con Abu Ibrahim, y le correspondió a éste. En cuanto al Califa, tomo en matrimonio a la hija de Maksan b. al-Mu'izz. Esta fue la madre del príncipe Ibrahim y del príncipe Isma'il'.

Aparte de este efecto anecdótico, que señala las rutas del poder en un sistema tribal sabemos que en 1204 se restauran las murallas, según nos cuenta Ibn Baškuwal. A partir de 1206 sabemos que el Rif queda en poder de los Banu Marin y que se produce una decadencia general de la economía por el exceso de impuestos al campo

A partir de aquí parece que los meriníes, en los siglos XIII-XIV tratan de dominar a Melilla desde Tlemcen y su fin, como ciudad musulmana, llega con la toma de Melilla por Pedro de Estopiñan, en 1497, una vez terminada la conquista de Granada. Hay que señalar que hubo una primera exploración en 1496, y que al año siguiente los castellanos obser- 
varon que los nativos se habían retirado. Desembarcaron con tablones previamente preparados con pintura simulando sillares, por lo cual cuando los nativos observaron que había una muralla no osaron atacar a los recién llegados, y cuando reacciónaron era demasiado tarde y ya eran fuertes en la plaza.

Para entonces debió ser un pequeño puerto mediterráneo, uno más de los muchos de la costa africana, sin pujancia ni relevancia especial, sólo citado en las cartas náuticas (Gozalbes, 1948).

Las descripciones de Melilla en época árabe son diversas y a veces confusas, como se podrá apreciar. Veamos los textos tal como han llegado:

En descripción de vías por el norte de Africa, mapa de Ibn Hawqal:

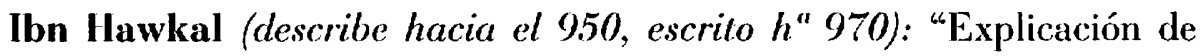
los nombres y textos contenidos en la tercera sección del mapa del Magreb.

Sobre el litoral inferior, se encuentran las ciudades siguientes, comenzando por la derecha Tenes, Orán, Wasalan, Araskul, Malila, Nakur, Ceuta, Tanger": Configuración del Mundo. p. 14.

"Malila era en otra época una ciudad ceñida por un muro fortificado y cuya prosperidad iba creciendo. El agua rodeaba la parte más grande de su muralla, y procedía de unos pozos de donde surgía un manantial potente.

La ciudad se remonta a tiempos lejanos en cuanto a su fundación se refiere.

Ella fue saqueada por Abu-l-Hassan Yauhar, el mismo que condujo a Egipto a los conquistadores del Magreb. Esta misma ciudad cayó en manos de la tribu beréber de los Banu Batuya.

Sus jardines bastaban a las necesidades de sus habitantes, asi como el gran volumen de los cultivos, granos y cereales; pero esto ha desaparecido en gran parte".

Nakur es en nuestra época, una ciudad de tamaño medio. Antiguamente era más importante, y sus ruinas son todavía visibles. Posee un puerto 
en el interior de una península llamada Mazimma, donde anclan los navíos". Configuración del Mundo. p. 29.

"El Wadi Muluya desemboca en el Wadi Sac, y ambos reunidos lo hacen en el mar, entre Yaraat Abi-l-'Ais y Malila”. Configuración del Mundo. p. 41.

Al-Bakri (h" 1067): Describe el camino de Uyda hacia Fez: "Se va de ella también hacia atrás y de ella hacia Maknas que es del pueblo de los Ahsad, $y$ de ella hacia "Ain al-Tin, $y$ de ella hacia la ciudad de Fez, y hay otro camino de Uyda hacia Melilla y hacia Saca..." :... . Melilla es un ciudad rodeada de una muralla de piedra y en su interior hay una qasbah poderosa. En ella hay una mezquita catedral, un baño y algunos zocos. Se dice que debe su reconstrucción a los Banu al-Bury b. Abi al-'Afiyah al-Meknasi. Cuando un comerciante llega a esta ciudad los habitantes, que son todos de los Urtada, echan a suertes cual de ellos debe encargarse de las operaciones comerciales a las cuales desea orientarse el extranjero. Este no puede hacer nada fuera de la vigilancia y supervisión de su nuevo patrono, que, por su parte, ha de proteger a su huésped contra aquellos que desearan hacerle mal. Para indemnizarse de esta molestia el patrono le exige una compensación, y, además, un regalo por los gastos de alojamiento.

Según Muhammad b. Yusuf ( $y$ otros escritores) esta plaza fue conquistada el año 314 (926-927 d. C.) por 'Abd al-Rahman al-Nasir li-Din Allah el cual hizo hacer la muralla de la ciudad para hacer un lugar de retirada para su partidario Musa b. al-'Afiya. En los versos siguientes Ahmed b. Muhammad b. Musa al-Razi hace alusión a esta circunstancia:

Y el rey, defensor de la religión de Dios * sin olvidar nada que pudiera proteger la fe Construyó para Musa, como lugar de retirada * una ciudad situada en alto, fuerte e invencible delante de la cual Tahert y los africanos habría de humillarse * y cuya construcción habría de superar a la de los Amalécios.

La medida de capacidad de la cual se sirven en Melilla se denomina Mudd y contiene 25 mudd(s) [modios] de los autorizados por el Profeta. El ratl, que es el mismo de Nakur, equivale a veintidós onzas, y cada onza pesa quince dracmas. El quintal que emplean para toda clase de usos es 
un múltiplo de este Ratl. La dracma se compone de una cierta cantidad de quilates, y cada quilate hace cinco octavos de la dracma legal.

El puerto de Melilla es bueno en estío. Enfrente está, en la costa andalusí, el puerto de Chelubina "Salobreña". Más adelante se indicará la serie de puertos que cubren el litoral, de oeste a este, desde Nakur a Melilla, y se hará conocer, simultáneamente, los nombres de los puertos andalusíes que encuentran en frente de ellos.

El viajero que parte del puerto de Melilla, dirigiéndose al este se encuentra primeramente el puerto de Yerua, de buen inuelle, cerca del cual hay un río que desemboca en el mar. De allí a las islas del Muluya (Las Chafarinas) hay ocho millas por tierra....etc.".

Al-Idrisi en el XII, habla del recorrido de Kerta a Melilla, distante 20 millas, y dice: "Melilla es una bella ciudad, de tamaño medio, rodeada de fuertes murallas y con una buena situación al borde del mar. Hubo, antes de la época actual, casas contíguas y muchas culturas. Hay un pozo alimentado por una fuente permanente cuya agua es abundante y sirve para el consumo de sus habitantes. Esta ciudad está en un medio beréber, de la rama de los Betaouia.

De Melilla a la desembocadura del río que viene de Akarsif, enfrente de esta desembocadura hay un pequeño islote, y en el desierto una pequeña ciudad de nombre Haraoua. Se cuentan 20 millas".

Yaqut al-Rumi: en el siglo XIV, se limita a decir "Malilat: bi-I-fatah Luma al-tasdid: Población (qariat) cercana a la costa del Mar Occidental". Muyam al-Buldan p. 189.

Juan León Africano, el interesante converso musulmán al cristianismo y posterior reversión al islam, nacido en Granada en 1487, muerto en Fez hacia 1562, dejó una interesante descripción de Melila, a mitad de camino entre lo real, lo recogido de otras fuentes y lo fantástico, empezando por su etimología del nombre de la ciudad. Este no puede corresponder a la idea de Miel, que no es radical ni en árabe ni en chelja (en árabe es 'asal). La incluye dentro de la región del Garet y dice: 
"Melela es una ciudad grande y antigua, edificada por los africanos sobre un cabo, en un golfo del Mediterráneo. Hace cerca de dos mil hogares, y fue cabeza de región, siendo por esta causa muy civilizada, y disponía de un condado extenso de donde se sacaba gran cantidad de hierro y miel, y por dicha razón fue llamada Melala, que así se llamaba en el idioma africano a la miel.

Antiguamente, en el mismo puerto de la ciudad cogían ostras con perlas. Durante un tiempo estuvo sometida esta ciudad a los godos, pero después fue reconquistada por los mahometanos y aquéllos huyeron a Granada, que dista de los mismos unas cien millas, es decir: cuanto de ancho tiene el mar en esta parte.

En los tiempos modernos, el Rey de España envió una escuadra para conquistarla, pero antes de que llegara [los nativos] tuvieron noticias y pidieron ayuda al rey de Fez, el cual, estando entonces ocupado en la guerra con los pueblos de Tamerma, envió un ligero ejército, y los habitantes, habiendo sido muy bien informados sobre la grandeza de la armada de los españoles, y desconfiando en poder contener el asalto, evacuaron la ciudad $\mathrm{y}$, con sus cosas, huyeron a los montes de Buthoia.

El capitán rey de $\mathrm{Fez}$, viendo lo sucedido, bien por hacer agravio a los de la ciudad, o por desprecio hacia los cristianos, puso fuego a todas las casas, quemando la ciudad. Esto ocurrió en 966 de la H. [1558 d. C.].

Después de este hecho llegó la armada de los cristianos, que se quejaron grandemente al ver la ciudad quemada y vacía. Ni por ésto la quisieron abandonar, sino que construyeron en la misma una fortaleza, y, poco a poco, volvieron a poner en pie todos los muros, y hoy son dueños de la misma". (LA, pp. 180-181) En esa zona describe la existencia de otro puerto, Chasasa, dedicado por los Fezies a su comercio con Venecia, que fue tomada y destruida por Fernando el Católico (LA, p. 181).

Poco se puede deducir de lo anteriormente dicho, excepto de que fue una pequeña ciudad, con quizás una $400-500$ casas a juzgar por el pequeño 
dato demográfico que tenemos. La existencia de sólo un pozo de agua como fuente de agua potable (aunque abundante) indica, de por sí; una población pequeña. Ningún dato altera la posibilidad de una mezquita y un baño, lo cual hace pensar que estaba todo en la alcazaba, junto con el agua, de manera que se aprecia una clara estructura del poder en urbanismo.

Desde un punto de vista militar se aprecia la existencia de dos recintos. de los cuales una alcazaba parece detentar el espacio físico sobre el cual se asentaba el poder. Siendo la fuente más antigua arfuí recogida del \pm 950 es posible pensar que las fortificaciones pudieran tener una relación técnica arquitectónica con lo que entonces se hacía en al-Andalus de tono oficialista. Evidentemente la fortificación llama la atención, y la referencia de al-Bakri a una muralla de piedra, a mediados del siglo siguiente, cuando había motivos para que pudiera sorprender, hace pensar que así debió ser, con un aparejo de soga y dos o tres tizones como posibilidad, siguiendo modelos cordobeses, que, como se sabe, estaban plenamente modulados y estructurados.

El sistema económico se basaba en cuatro soportes: la huerta, como elemento de alimentación primaria, la pesca de perlas como sistema de atracción de mercaderes a un lugar pequeño, la explotación de los citados mercaderes cuando iban a comerciar y finalmente la situación como principio y fin de etapa en los viajes costeros a pie que unían Orán con Tanger y que parecen haber permanecido inconmovibles hasta casi nuestros días. Esto es, resumídamente lo que puede decirse sobre Melilla y su entorno, que indudablemente le afectó.

LA POSIBLE VIDA MATERIAL DI: MELILLA EV FPOCA ARABE: UN "RIVVVAL"

Ahora, para finalizar, veamos algo de materiales que pudieron ser visibles en Melilla entre los años que afectan al tema de nuestra exposición. Evidentemente no por necesidad tuvieron que ser exactamente éstos los objetos, pero si podemos darnos una idea de lo que pudo conocerse en esta ciudad entre los siglos IX-XV. Tampoco hay que considerar que fueran los únicos tipos de objetos, pero pueden dar imágen. Para ello se ha ordenado por fotos. 


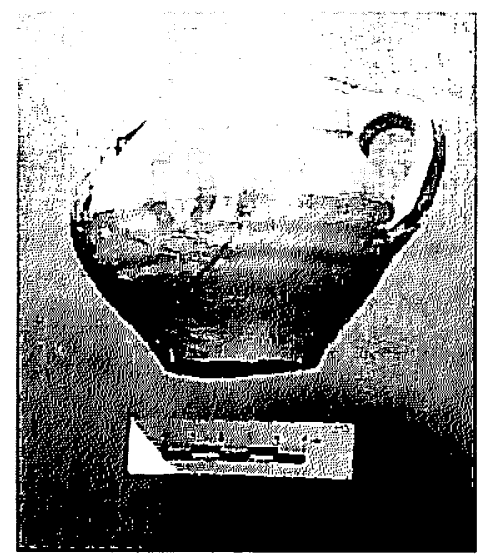

Pequetia tarilla o jarritu de um asa. a torzo, fondo conve xo, con decormetion de rayas vericales. de tomo oxre. Posible jarrillo para sobladas. S. X. Procede de: Alenla dr l lenares (Madridj.

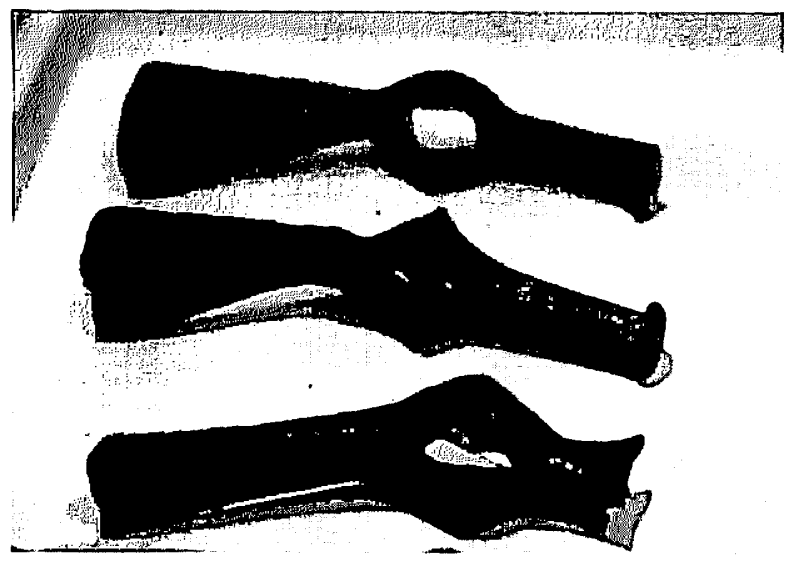

Piras para trabajar tierra " cunterin the poca dureza. Iliero forjmk. Siglo X final. Prowere (le Lititor (Albacte) 


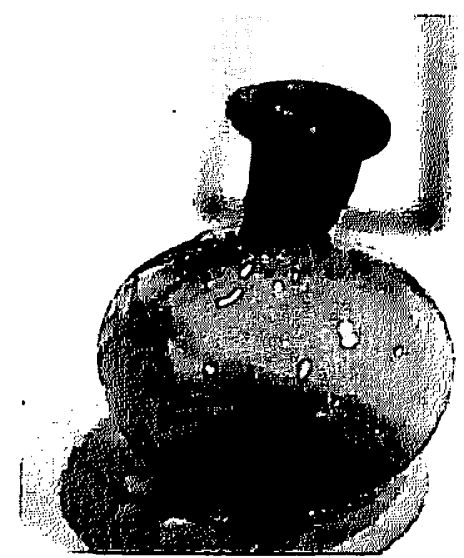

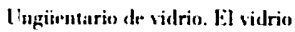
[ite muterial raru!

posilbemente caro. Esta pieza

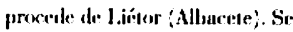
usi parn aplicar afteites. $y$ va assurim tu tarmbién con los baños.

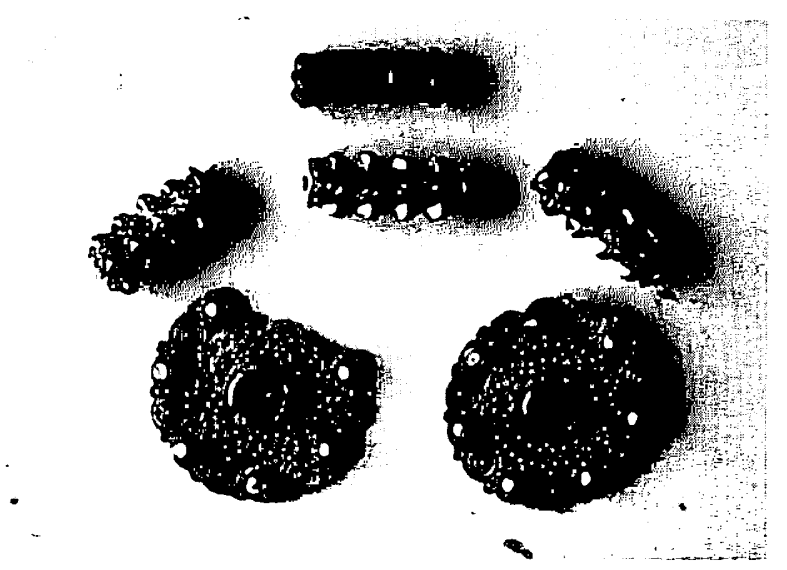

Bricreas y turne de oro. lats jeyas furcron variudtas. pero m-1e lipo,

rool sus ligeras variacionem,

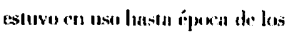
almohaules. lass brintoms tienen

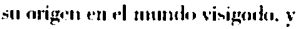
se cosian a la topti. I .om lutes son elementos de coullares.

distingusienlose comutom,

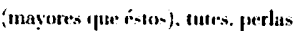

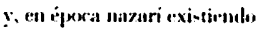

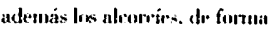

piransidal y low atlamares.

(Procredencia decomoriala). 


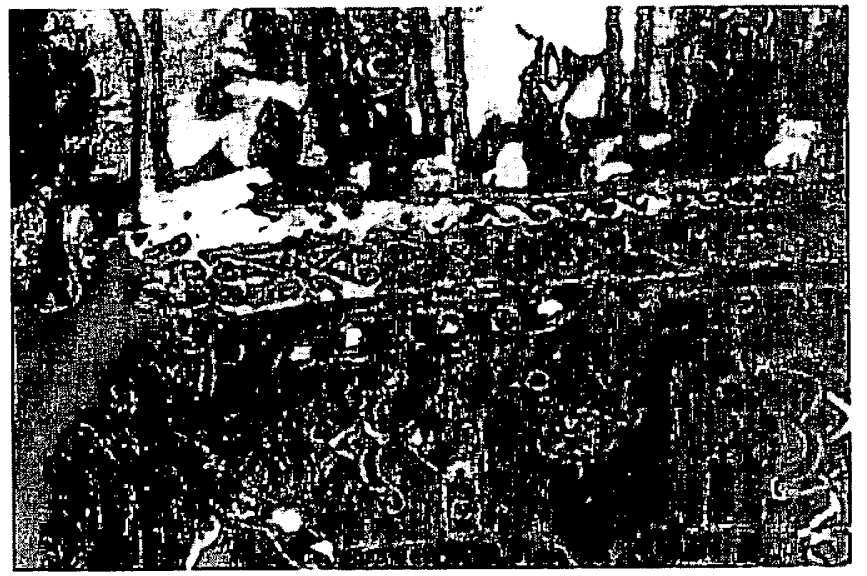

Se citan lambién bores de marfil. Es presumible que

fueran purecidos a éste. Scrvian. presumiblemente. para conservar algodones empapados en perfunes y otros ufeites. En ete caso se aproria una escena de sorte y una decoración con atributus renles. (Musen del Louvre. Pario).

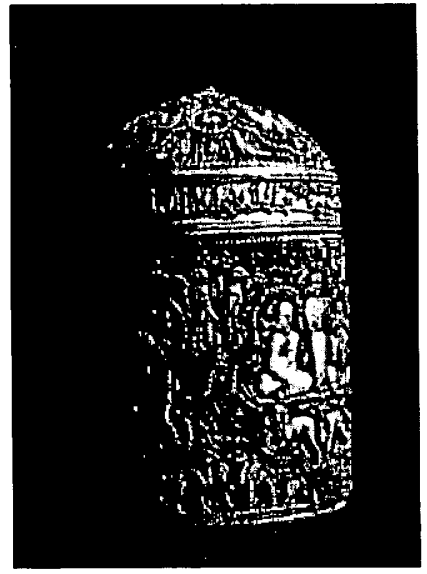

Entre los prosentes que se cilan más arriba se mencionan tejidus del tiraz rordohés. con letras bordadas. Esic es el caso que: aquí se muestra, procedente de Córcluba, de época de 'Abd al-Italumun III. en tormo al y29 d. C. (Parrorpuia de Oña. Burgyos). 


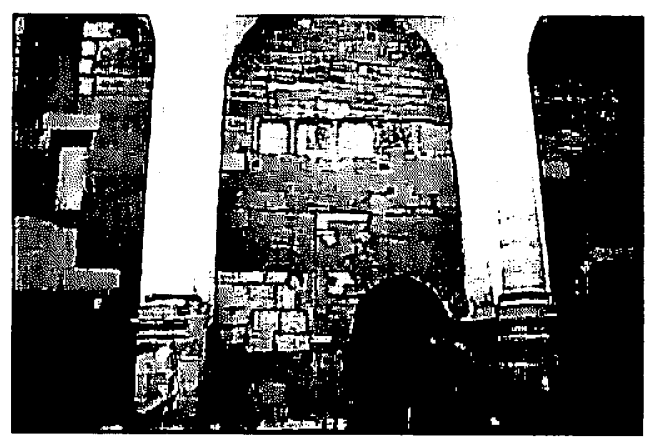

Se loubha de la inezpuita catedral dr. Mlrlillia, y de la crual pricticmume mudu más se sable. Fin pretumible rue el muro de la tibla estuvirra decorade ron ulgo purrecido a esta en ipora del rolifato cordobes (Meziguila mayor, o de ln iglesia de San luant, Mlmeriaj.

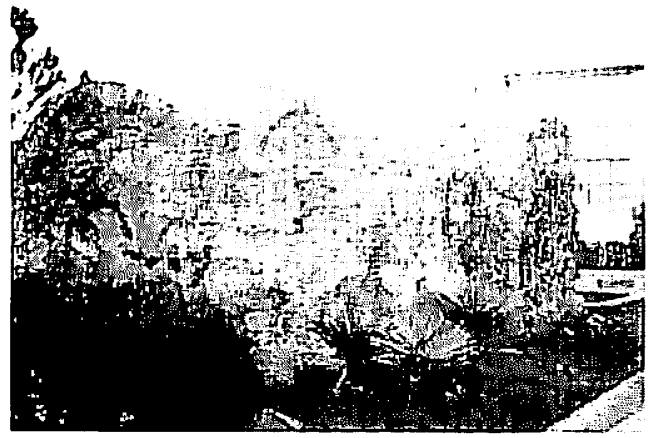

Acoriackes com la mezuguita irian los Burius. Tampuco quedan, o imo hat sido iclentificados, los metes ale les banios para hacer mpropiacluneruc las abluciones anles ile ir a rezar. Los betronos tenian tambicin nuna función social. celebrindose en ellos espunsisales, loodas y cirrancisinnes. P'ara los baños propiamente diction se reservulsun turnes para hombres y unujere. 'baños de Ceruta!. 
En las pipocas finnles del Islan de al-Andalus, en tarnu ul siglo XII]-XIV la cortunicu popular seguia esquetras de un sólo color oscuro sobre el foindo claro de la pasta, de caricicr espuenático. Esta produccion es caracteristicn do: la zonn granadino-aluwcriense, presumiblemente: se relutionu con las cerimicas lecribures coetáneas (Museo de Aluneríà.

Además de las sencillas piezas populares como la de la foto 10, que sabenos que se hicieron en d Norte de Africa, Iumbién se hizo una cerámica de mis lujo. de unganeso bajo vidriados verde. en Granada. Jista reránica llegó también al Nor1e de Africa (Museo Arqueológico Nacional. Mactrid).
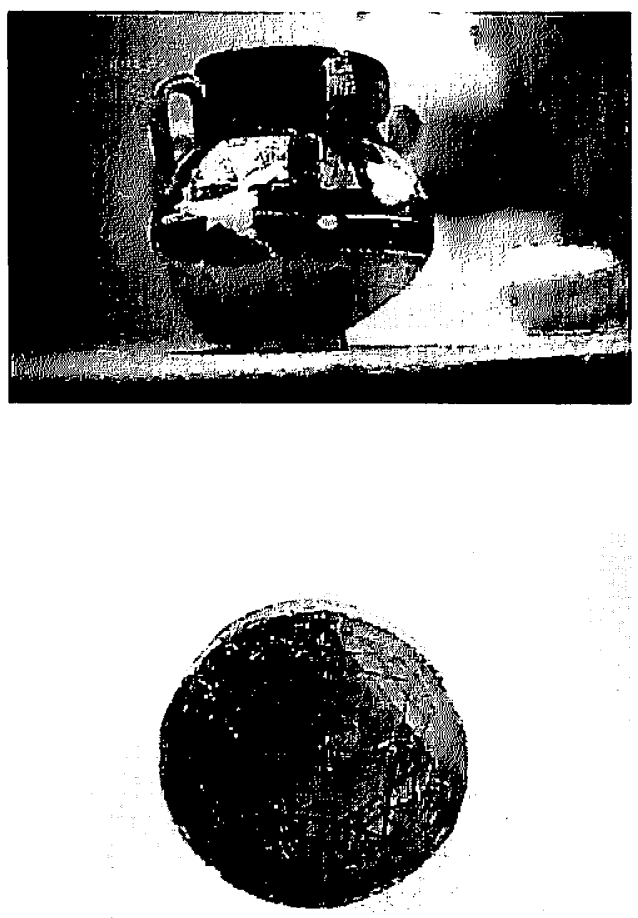

Evidentemente pueden rastrearse más elementos, pero la idea fundamental que se debe retener con cierto criterio de certeza es el material aquí presentado, dentro de lo que no deja de ser un aspecto teórico. 
Canto (istreia, $A$ (1991): "De ln ceca $A 1-$-Audalus a la de Madinat al-Zahra". en Comadernos de Madinat al Zahra'3, pp. 111-121.

Gozalhes (iraviotto. E.: Atlas Arquteológico de] Marruecos Mediterráneo. Granada. 1982.

- "Melilla, ciudad musulmama" en I Congreso hispanu-africano de las culturas unediterráneas. Velilla. 1984, pp. 175-184.

Voz Melilla Fincyclopedie de I'Islam. Tiomo VI, Ninuello Seric. Leyden., 1900-19-.

Vaz Melilla. Finciclopedia Espasa. Maılricl.

Mir Berlanga. I'. Restumen de historia de Melilla. Melilla. $190 . \overline{5}$.

Terún. M. Imago Mundi. Madrid. 1964.

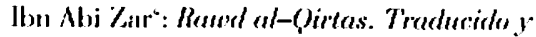
anotrato per A. Ilucici Miranda. Valencia, 1964. en Serie T'extos Medievales. 12.

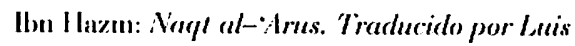
Seco de Lacena. Texto cirabe por C. P. Siegbold. Indices por : M" Milagros Carcel Orti. Valencia. 197t. lin Texton Medievales, 39.

Ibn Ilawkal: ('omfiguracion del mumde.. (Fragmentos alusin'os al Magreb y Espana). Trraducción o indices por Maria José Remumi Suan: Valeuria. I9?1 en Textos Medievales, 26.

Ibu llayyan. de Córdoha: Crónica del Califa Abdarrahman III an-Nasir entre los años 9/2y. 942 (al-1/luclubis 1). Traducción e indices por M"Jessis Vignern y Federico Corriemte.

Preliminar por José $M^{\prime \prime}$ Lacarra. Zaragoza, 1981. Fa 'Tixios Medievales, 64.

Ilon 'Ilari: Al-Bayan al-Mugrib. Nueress fragmentos almorárides y almohades. Trud. y. anotartos por A. Imici Miranda. Valencia. 1963. en Serie Textos Medievales. 8.

Crónica: de Alfonso III. Ed. Zararias Garrió Villende. Madriel. 1918.

Al-Idrissi, al-Saril: Kitalu muzhr-l-mustanifi ijtiraqi-l-affugi. Amsterdam. 1968 (Rrimp).

León Aricamo, ,luan (al-Hasan b. Mulaummand b. al-Wayatu al-Fusi al-Carnati). Descripcion de Africa. Tetuan, 1942.

Levi-Provengal. E: Documents inédits allistoire almohude. Fragments mamuscrits du "legajo" 1919 du fonds arabe de LEscurial. Paris. 1928.

"Magnussimenues saga" en Snorres kemge Sagaer. (0slo, 1943.

'Abd Allalı l. ol-'Axiz al-Bakri: A-Magribu fi dikri biladi Ifriqugati wa-l-Magribi min Kilabi al-mosuliki wn-t-mamaliki. Francoforte. 1996. Yaqut al-Rumi:: Muyñam al-Buldan. Dar al-Sabr. Beirut. 1986. Tomo V. 